\title{
Plant genotype determines biomass response to flooding frequency in tidal wetlands
}

\author{
Svenja Reents ${ }^{1}$, Peter Mueller ${ }^{2}$, Hao Tang ${ }^{1}$, Kai Jensen $^{1}$, and Stefanie Nolte ${ }^{3,4}$ \\ ${ }^{1}$ Applied Plant Ecology, Institute of Plant Science and Microbiology, Universität Hamburg, Hamburg, 22609, Germany \\ ${ }^{2}$ Smithsonian Environmental Research Center, Edgewater, Maryland 21087, USA \\ ${ }^{3}$ School of Environmental Sciences, University of East Anglia, Norwich, NR4 7TJ, UK \\ ${ }^{4}$ Centre for Environment, Fisheries and Aquaculture Science, Lowestoft, NR33 0HT, UK
}

Correspondence: Svenja Reents (svenja.reents@uni-hamburg.de)

Received: 20 March 2020 - Discussion started: 9 June 2020

Revised: 30 November 2020 - Accepted: 1 December 2020 - Published: 18 January 2021

\begin{abstract}
The persistence of tidal wetland ecosystems like salt marshes is threatened by human interventions and climate change. In particular, the threat of accelerated sea level rise (SLR) has increasingly gained the attention of the scientific community recently. However, studies investigating the effect of SLR on plants and vertical marsh accretion are usually restricted to the species or community level and do not consider phenotypic plasticity or genetic diversity. To investigate the response of genotypes within the same saltmarsh species to SLR, we used two known genotypes of Elymus athericus (Link) Kerguélen (low-marsh and high-marsh genotypes). In a factorial marsh organ experiment we exposed both genotypes to different flooding frequencies and quantified plant growth parameters. With increasing flooding frequency, the low-marsh genotype showed higher aboveground biomass production compared to the high-marsh genotype. Additionally, the low-marsh genotype generally formed longer rhizomes, shoots and leaves, regardless of flooding frequency. Belowground biomass of both genotypes decreased with increasing flooding frequency. We conclude that the low-marsh genotype is better adapted to higher flooding frequencies through its ability to allocate resources from below- to aboveground biomass. Given the strong control of plant biomass production on salt-marsh accretion, we argue that these findings yield important implications for our understanding of ecosystem resilience to SLR as well as plant species distribution in salt marshes.
\end{abstract}

\section{Introduction}

Salt marshes are wetland ecosystems predominantly found along coastlines, where they form a transition zone between the marine and the terrestrial environment. Salt marshes provide important ecosystem services like protection of coastlines against storm surges by wave attenuation (Möller et al., 2014), supply of nursery grounds for commercially important fish (Bolle et al., 2009) and mitigation of climate change by long-term carbon sequestration (McLeod et al., 2011). However, human interventions such as land reclamation, eutrophication and climate change threaten the persistence of salt marshes, causing loss rates of $1 \%-2 \%$ of the global area per year (Duarte et al., 2008). In particular, the threat of accelerated sea level rise (SLR) has increasingly gained the attention of the scientific community recently (Fitzgerald et al., 2008; Kirwan and Megonigal, 2013; Schuerch et al., 2018).

Generally, up to a certain locally varying threshold of SLR, salt marshes are able to keep up with rates of SLR through their ability to accrete vertically (Kirwan and Megonigal, 2013). During this process, salt-marsh plants act as ecosystem engineers because their aboveground biomass reduces water flow velocity and hydrodynamic forces, which results in a decrease in the sediment-loading capacity of the water and an increase in sediment settlement (Morris et al., 2002; Yang, 1998). Furthermore, a high belowground biomass production and decreased decomposition rates in oxygendeficient soils lead to an accumulation of organic matter and thereby expansion of soil volume. Whether above- or belowground processes predominantly contribute to verti- 
cal accretion depends on the marsh type (i.e. minerogenic vs. organogenic) and often depends on local tidal amplitude (Allen, 2000; Kirwan and Megonigal, 2013; Nolte et al., 2013b). Yet, in both cases, biomass production of the marsh vegetation is an important driver of accretion. When accretion rates are too low and threshold values of SLR are exceeded, plant growth is negatively affected, leading to a negative feedback loop, which ensues marsh submergence and finally marsh loss (Chmura, 2013; Kirwan and Guntenspergen, 2012).

Recently, more studies have therefore been focusing on salt-marsh resilience to projected rates of SLR by studying the vegetation response. To examine how vegetation responds to changes in flooding regimes, so-called "marsh organ" experiments have been proven to be convenient and insightful approaches. A marsh organ consists of several mesocosms arranged next to each other and along an elevational gradient. Kirwan and Guntenspergen (2012), for example, placed a marsh organ in a brackish marsh to examine the effect of varying sea levels on plant growth of two marsh species and what possible implications this may have on accretion processes. They observed that marsh elevation within the tidal frame determines whether root biomass increases or decreases with SLR. In contrast to belowground productivity, aboveground biomass response was species dependent. Numerous other studies confirmed that responses of marsh plants to sea level changes are highly species specific (Eleuterius and Eleuterius, 1979; Kirwan and Guntenspergen, 2015; Langley et al., 2013; Morris et al., 2013). Therefore, the effect of SLR on plant biomass production, and thus the ability of the ecosystem to accrete vertically, can only be understood if SLR-induced shifts in plant species composition also are taken into account.

However, such studies on the effect of SLR on plants are usually restricted to the species or community level (Kirwan and Guntenspergen, 2015; Langley et al., 2013; Morris et al., 2013). They usually do not consider the high degree of phenotypic plasticity and genetic diversity within many species, as for instance evident between different locally adapted populations (Valladares et al., 2014). Yet, understanding a species' adaptive genetic plasticity can be crucial to evaluating its response to environmental change (Razgour et al., 2019). Indeed, in some cases environmental change can in fact induce larger variability in plant biomass production within than between species (Beierkuhnlein et al., 2011). We therefore argue that intraspecific differences in the biomass response to SLR of salt-marsh plants are likely relevant and require more attention by the scientific community to understand ecosystem resilience.

To investigate the response of genotypes within the same salt-marsh species to SLR, we used two known genotypes of the grass Elymus athericus (Link) Kerguélen. This species is widely distributed in NW European salt marshes and usually grows in high-elevated and therefore less frequently flooded zones of the salt marsh (i.e. high marsh) (Nolte et al., 2019).
In the high marsh, the tall grass forms dense, monospecific stands with a low local plant species diversity (Bakker et al., 2003). Recently, however, populations of E. athericus have been observed spreading into lower and thus more frequently flooded zones of the marsh (i.e. low marsh) (Olff et al., 1997; Veeneklaas et al., 2013). Low- and high-marsh genotypes are visually distinguishable, as the low-marsh genotype develops a specific phenotype different from the high-marsh genotype (Bockelmann et al., 2003). If genotypes respond differently to increased flooding frequencies, for instance in biomass productivity, it might affect salt-marsh responses to SLR.

The aim of this study was to investigate potential adaptations of the low-marsh genotype to increased flooding frequencies, to improve current evaluations of salt-marsh resilience to SLR. To test the hypothesis that the low-marsh genotype performs better at increased flooding frequencies than the high-marsh genotype, which would be reflected in above- and belowground growth parameters like biomass production and shoot, leaf and rhizome lengths, we conducted a factorial marsh organ experiment. We exposed both genotypes of $E$. athericus to three different flooding frequencies and quantified plant growth parameters to compare their performance and assess morphological adaptations of the low-marsh genotype.

\section{Material and methods}

\subsection{Plant collection and culture}

Plants were collected in April 2015 from a salt marsh on the Dutch island Schiermonnikoog $\left(53^{\circ} 30^{\prime} \mathrm{N}, 6^{\circ} 16^{\prime} \mathrm{E}\right)$ from stands that have previously been identified to be dominated by genetically distinct populations of E. athericus, i.e. highmarsh (HM) and low-marsh (LM) genotypes (Bockelmann et al., 2003). On Schiermonnikoog, Elymus athericus can be found in higher and lower-elevated sites, which are inundated 20-125 and 90-270 times per year, respectively (Bockelmann et al., 2003). Soil salinities range from 22 to $29 \mathrm{ppt}$ (Bolhuis et al., 2013). Plants and soil were extracted in the form of intact sods to keep them alive during transport. In Hamburg, soil was removed and roots were rinsed before both genotypes were planted separately in trays with standardised potting soil. Until the start of the experiment (i.e. for 24 months), plants were kept under identical environmental conditions in a common garden at the Institute of Plant Science and Microbiology. Ramets of these plants were used for this study. In July 2017, single plants of similar biomass were selected based on visual assessment (no obvious outliers), transplanted to separate pots and randomly assigned to the flooding treatments (described in Sect. 2.2). Initial shoot length and shoot number were tested for differences between genotypes and flooding frequencies to ensure that results were not biased by unequal plant size at the beginning of the experiment. There were no significant 
differences regarding shoot length (genotype: $F=0.787$, $p=0.380$; flooding frequency: $F=0.127, p=0.881$; genotype flooding frequency: $F=0.231, p=0.795)$ and number of shoots (genotype: Wald $=2.203, p=0.137$; flooding frequency: Wald $=0.357, p=0.837$; genotype $\cdot$ flooding frequency: Wald $=0.005, p=0.997)$. The pots were $15 \mathrm{~cm}$ in diameter, were $17 \mathrm{~cm}$ in height and had holes in the bottom to facilitate drainage. They were filled with salt-marsh soil taken from the salt marsh at Sönke-Nissen-Koog, Germany $\left(54^{\circ} 36^{\prime} \mathrm{N}, 8^{\circ} 49^{\prime} \mathrm{E}\right)$, which was sieved (with a $1 \mathrm{~cm}$ mesh) and homogenised beforehand (see Nolte et al., 2013a, for soil properties). Eight replicates (i.e. single plants in separate pots) per genotype were assigned to one of three flooding treatments, so that a total number of 48 plants were used in this study.

\subsection{Experimental setup}

Plants were placed onto three steps (step height: $20 \mathrm{~cm}$ ) within a tidal-tank facility (Hanke et al., 2015) to create three different flooding frequencies. The tidal tank is located outdoors at the Institute of Plant Science and Microbiology and has a total volume of $6.75 \mathrm{~m}^{3}$ (dimensions: $3 \mathrm{~m} \times 1.5 \mathrm{~m} \times 1.5 \mathrm{~m}$ ). A pump was used to fill and empty the tidal tank at regular intervals to mimic tides by alternating between three different maximum water levels. Pots were fully drained between flooding events. Flooding with the respective maximum water level reached $3 \mathrm{~cm}$ above soil surface, lasted $2 \mathrm{~h}$ and took place twice a day. The lowest step was flooded every day, which represented the highest frequency. The flooding of the middle step (moderate flooding frequency) happened weekly, while plants on the highest step were flooded only every 2 weeks (lowest flooding frequency). Highest and lowest flooding frequency reflect the natural flooding gradient between the pioneer zone and high marsh in many NW European salt marshes, including the site where our plants were collected (Bockelmann et al., 2002). A CTD diver combined with a baro diver (Van Essen Instruments, Delft, the Netherlands) was used to monitor flooding cycles. Artificial sea salt (AB Aqua Medic GmbH, Germany) was suspended in tap water to create a salinity of about 20 22 ppt. To minimise the impact of other effects than flooding frequency and genotype, the pots were circulated on each step, and other seedlings and algae were removed once a week. Concurrently, water level and salinity were checked as well. The experiment ran for approx. 12 weeks from midJuly to early October 2017.

\subsection{Measurements}

\subsubsection{Biomass}

At the end of the experiment (2 October 2017), the plants were harvested, separated into above- and belowground biomass, dried for $2 \mathrm{~d}$ at $70^{\circ} \mathrm{C}$, and weighed. Belowground biomass was divided into rhizomes and roots and weighed. The length of rhizomes was also recorded. Additionally, above- and belowground biomass were used to calculate the belowground : aboveground ratio.

\subsubsection{Plant growth}

At the beginning and the end of the experiment, plant shoot and leaf length as well as number of shoots and leaves were measured. The difference between both measurements was calculated and designated as $\Delta$. Only living plant material was taken into account, and length measurements (leaf and shoot length) were carried out on the longest leaves or shoots.

\subsection{Statistical analysis}

Data were tested for normality by applying the Shapiro-Wilk test. Except count data (e.g. number of leaves), all parameters were normally distributed and therefore further analysed applying factorial ANOVAs (analyses of variance). Due to the well-balanced study design, potential moderate deviations from homogeneity of variance between groups were considered unimportant for ANOVA testing (Box, 1954; McGuinness, 2002). Each analysis included genotype and flooding frequency as well as their interaction as explanatory variables. To detect significant differences between treatments (flooding frequency and genotype), post hoc tests (Tukey's honestly significant difference, HSD) were conducted. To analyse count data, i.e. number of shoots and number of leaves, generalised linear models (GLMs) were applied assuming a Poisson distribution and including the explanatory variables genotype and flooding frequency, as well as twoway interaction effects. Each GLM was checked for overdispersion (Pearson $\chi^{2}$ dispersion parameter) and was refitted afterwards if necessary, using the standard procedure of the applied program. All statistical analyses were performed using Statistica 13 (StatSoft Inc., Tulsa, OK, USA).

\section{Results}

\subsection{Biomass}

Total biomass, defined as the sum of dry above- and belowground plant biomass, differed significantly between genotypes and flooding frequencies (Table 1). In addition, the interaction of both factors showed a significant effect on total biomass. Total biomass production of the high-marsh genotype decreased steadily with increasing flooding frequency, whereas the total biomass of the low-marsh genotype decreased less distinctly (Fig. 1a). The difference between low-marsh and high-marsh genotypes was most pronounced at the highest flooding frequency. In fact, the low-marsh genotype produced almost twice as much total biomass at the highest flooding frequency as the high-marsh genotype 
Table 1. Summary statistics of main response variables in the experiment testing for effects of flooding and genotype of Elymus athericus on its biomass and growth. Count variables (number of shoots, number of leaves) are analysed through GLM; all other variables are analysed by a two-way factorial ANOVA. Significant $p$ values are shown in bold letters. Means and standard errors are shown in Figs. 1 and 2.

\begin{tabular}{|c|c|c|c|c|c|c|c|}
\hline \multirow[b]{2}{*}{ Response variable } & \multirow[b]{2}{*}{ Statistical test } & \multicolumn{2}{|c|}{$\begin{array}{l}\text { Genotype } \\
(\mathrm{df}=1)\end{array}$} & \multicolumn{2}{|c|}{$\begin{array}{l}\text { Flooding frequency } \\
\qquad(\mathrm{df}=2)\end{array}$} & \multicolumn{2}{|c|}{$\begin{array}{l}\text { Genotype } \cdot \text { flooding } \\
\text { frequency }(\mathrm{df}=2)\end{array}$} \\
\hline & & Test statistic & $p$ value & Test statistic & $p$ value & Test statistic & $p$ value \\
\hline Total biomass [g] & factorial ANOVA & $F=13.18$ & $\leq 0.001$ & $F=18.24$ & $\leq 0.001$ & $F=3.36$ & $\leq 0.05$ \\
\hline Aboveground biomass [g] & factorial ANOVA & $F=13.84$ & $\leq 0.001$ & $F=6.38$ & $\leq \mathbf{0 . 0 1}$ & $F=4.77$ & $\leq 0.05$ \\
\hline Belowground biomass [g] & factorial ANOVA & $F=4.31$ & $\leq \mathbf{0 . 0 5}$ & $F=21.93$ & $\leq 0.001$ & $F=0.53$ & 0.59 \\
\hline$\Delta$ Shoot length $[\mathrm{cm}]$ & factorial ANOVA & $F=7.77$ & $\leq 0.01$ & $F=0.32$ & 0.73 & $F=1.03$ & 0.37 \\
\hline$\Delta$ Leaf length $[\mathrm{cm}]$ & factorial ANOVA & $F=5.09$ & $\leq \mathbf{0 . 0 5}$ & $F=1.08$ & 0.35 & $F=1.42$ & 0.25 \\
\hline$\Delta$ Number of shoots & GLM & Wald $=0.00$ & 0.95 & Wald $=5.87$ & 0.05 & Wald $=0.78$ & 0.68 \\
\hline$\Delta$ Number of leaves & GLM & Wald $=0.44$ & 0.51 & Wald $=19.69$ & $\leq \mathbf{0 . 0 0 1}$ & Wald $=1.60$ & 0.45 \\
\hline Root biomass [g] & factorial ANOVA & $F=0.03$ & 0.86 & $F=10.69$ & $\leq 0.001$ & $F=0.07$ & 0.93 \\
\hline Rhizome biomass [g] & factorial ANOVA & $F=6.49$ & $\leq \mathbf{0 . 0 5}$ & $F=3.84$ & $\leq \mathbf{0 . 0 5}$ & $F=0.51$ & 0.60 \\
\hline Rhizome length [cm] & factorial ANOVA & $F=6.10$ & $\leq 0.05$ & $F=1.67$ & 0.20 & $F=0.45$ & 0.64 \\
\hline Belowground : aboveground & factorial ANOVA & $F=0.34$ & 0.56 & $F=14.56$ & $\leq \mathbf{0 . 0 0 1}$ & $F=0.13$ & 0.88 \\
\hline
\end{tabular}

(LM: $4.61 \pm 0.70 \mathrm{~g}$, HM: $2.66 \pm 0.52 \mathrm{~g}$, mean \pm standard deviation).

Genotype and flooding frequency as well as their interaction had a significant effect on the aboveground biomass production. Aboveground biomass of the high-marsh genotype decreased with increasing flooding frequency from $3.31 \pm 0.57 \mathrm{~g}$ to $2.03 \pm 0.38 \mathrm{~g}$ (Fig. 1b). However, aboveground biomass production of the low-marsh genotype remained constant at about $3.46 \pm 0.45 \mathrm{~g}$ on all flooding frequencies.

In contrast to the genotype-specific aboveground biomass response to flooding, belowground biomass of both genotypes decreased with increasing flooding frequency (Fig. 1c). Results indicate a more pronounced effect of flooding frequency on belowground biomass production compared to the factor genotype (Table 1). Under all flooding frequencies, the low-marsh genotype produced slightly more belowground biomass than the high-marsh genotype (LM: $1.63 \pm 0.78 \mathrm{~g}$, HM: $1.30 \pm 0.76 \mathrm{~g}$ ).

Root biomass production (belowground biomass without rhizomes) was significantly affected by flooding frequency $(F=10.69, p<0.001)$ but did not differ between genotypes. Root biomass decreased with increasing flooding frequency for both genotypes (Fig. 1d). In contrast, biomass of rhizomes was significantly affected by both genotype and flooding frequency (Table 1). Mean rhizome biomass of the low-marsh genotype was higher than of the highmarsh genotype (LM: $0.55 \pm 0.50 \mathrm{~g}, \mathrm{HM}: 0.26 \pm 0.28 \mathrm{~g}$ ), with the most pronounced differences on lowest and highest flooding frequency (Fig. 1e). In some cases, the lowmarsh genotype formed very long rhizomes (up to $166 \mathrm{~cm}$ length, coiled around the soil). On average, rhizomes of the low-marsh genotype were nearly twice as long as those of the high-marsh genotype (LM: $51.43 \pm 41.11 \mathrm{~cm}$, HM: $26.63 \pm 27.23 \mathrm{~cm}$, Table 2). Genotypes significantly differed in the length of rhizomes $(F=6.102, p<0.05$, Table 1$)$. The belowground: aboveground ratio was significantly affected by flooding frequency (Table 1) and decreased with increasing flooding frequency (Fig. 1f).

\section{2 $\Delta$ Leaf and shoot length}

The increase in shoot and leaf length significantly differed between genotypes (Table 1). Regarding leaf length, the high-marsh genotype showed approximately the same increase in all flooding frequencies $(1.9 \pm 4.45 \mathrm{~cm})$. The lowmarsh genotype had similar increases in leaf lengths at the lowest flooding frequency but showed pronounced increases in leaf length with increasing flooding frequency $(7.03 \pm 2.17 \mathrm{~cm})$ (Fig. 2a). Increase in shoot length of the low-marsh genotype was twice as high as that of the highmarsh genotype (LM: $10.78 \pm 6.18 \mathrm{~cm}, \mathrm{HM}: 5.57 \pm 6.58 \mathrm{~cm}$, Fig. 2b).

\section{3 $\Delta$ Number of leaves and shoots}

Neither genotype nor flooding frequency had a significant effect on the increase in number of shoots (Table 1). However, for the increase in number of leaves, a significant effect of flooding frequency was detected (Wald $=19.69, p<0.001$ ). With highest flooding frequency, both genotypes produced the lowest number of new leaves (LM: 10.4 \pm 4.0 , HM: $8.9 \pm 2.1$; Table 2).

\subsection{Discussion}

Assessments of plant responses to changed hydrological conditions (e.g. SLR) have thus far focused mainly on comparisons on the species level. However, variability in plant responses within species can be considerably higher than between species (Beierkuhnlein et al., 2011). In this study, we 

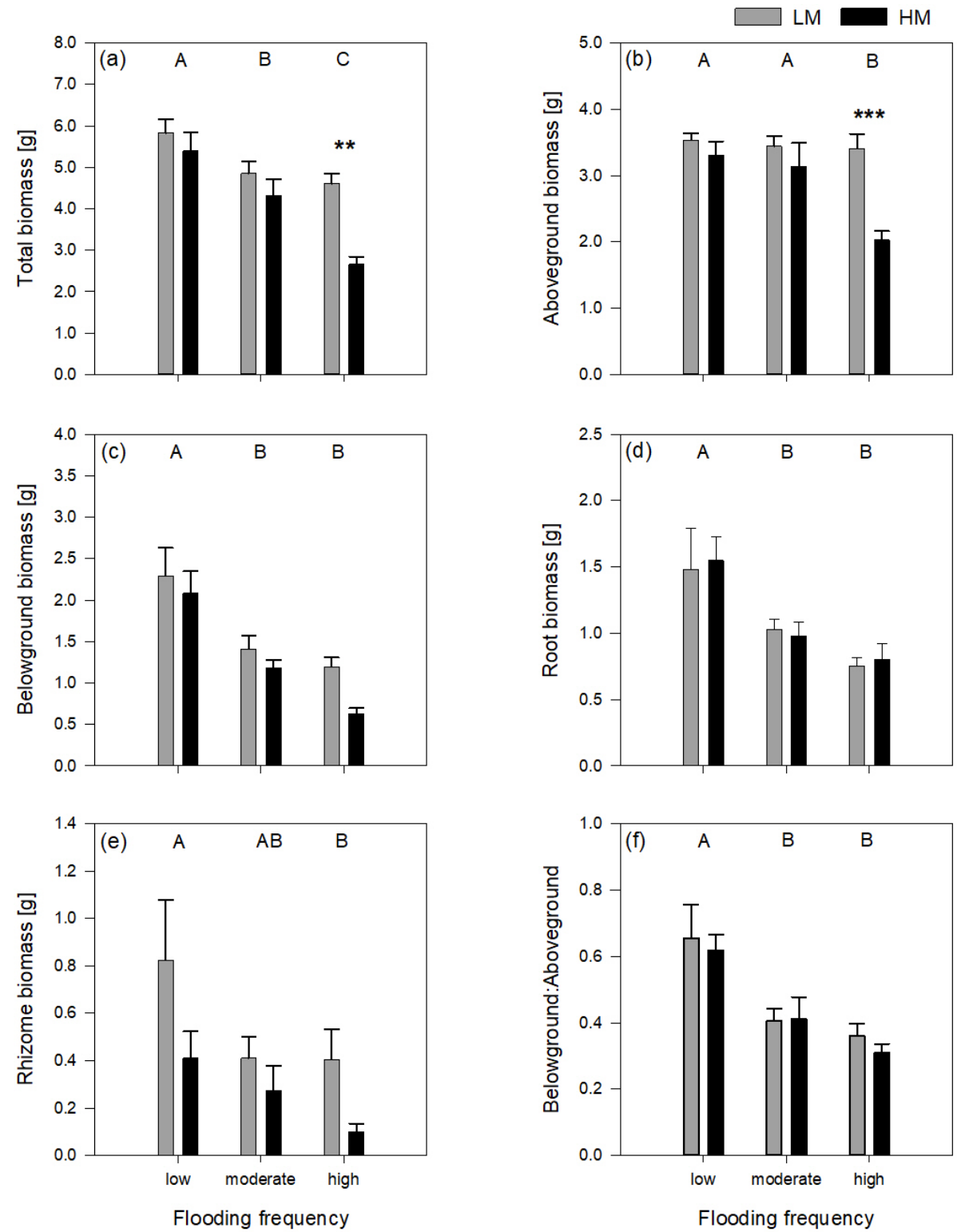

Figure 1. Total biomass (a), aboveground biomass (b), belowground biomass (c), root biomass (d), rhizome biomass (e) and belowgroundaboveground ratio (f) of both genotypes on three different flooding frequencies (mean + standard errors). Stars show significant differences between low-marsh (LM) and high-marsh (HM) genotypes within the same flooding treatment based on Tukey's HSD post hoc test $\left(^{*} p<0.05 ;{ }^{* *} p<0.01 ;^{* * *} p<0.001\right)$. Capital letters indicate significant differences between flooding frequencies. For statistics see Table 1.

therefore investigated differences in plant response between genotypes of the same species (Elymus athericus) to better understand the importance of intraspecific variability for evaluations of future ecosystem functionality and resilience. We found, in line with our hypothesis on biomass production, that the low-marsh genotype performs better than the highmarsh genotype under increased flooding frequency. Additionally, the low-marsh genotype generally formed longer rhizomes, shoots and leaves, regardless of flooding frequency (Figs. 1 and 2). We argue that these findings yield important implications for our understanding of ecosystem resilience to SLR as well as plant species distribution in salt marshes.

We found a higher total biomass of the low-marsh genotype, which was particularly pronounced under high flooding frequency (Fig. 1a). This result indicates a better adaptation of the low-marsh genotype to lower-elevated, more frequently flooded conditions. When separating above- and belowground biomass, the high-marsh genotype showed a decrease in both biomass parameters with increasing flooding frequency. Aboveground biomass is important for maintain- 

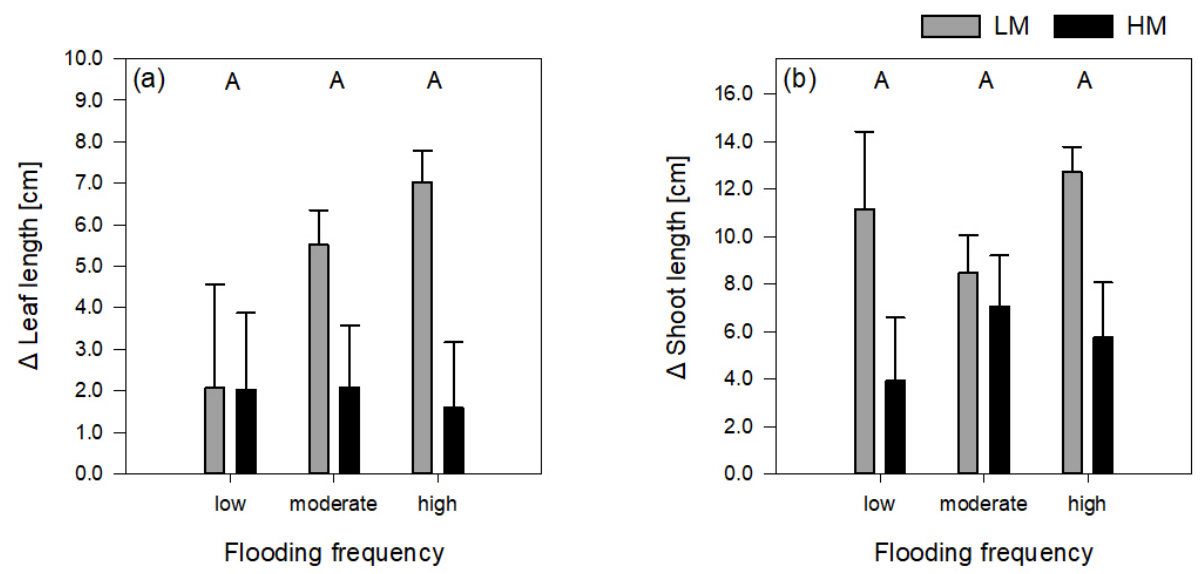

Figure 2. Delta leaf length (a) and delta shoot length (b) of both genotypes on three different flooding frequencies (mean + standard errors). Capital letters indicate significant differences between flooding frequencies. For statistics see Table 1.

Table 2. Mean and standard error (SE) of rhizome length [cm], delta number of leaves and delta number of shoots for different combinations of factors genotype and flooding frequency. LM: low-marsh genotype, HM: high-marsh genotype.

\begin{tabular}{llr|rr|rr|r|rr}
\hline & & & \multicolumn{2}{|c|}{$\begin{array}{c}\text { Rhizome length } \\
{[\mathrm{cm}]}\end{array}$} & $\begin{array}{c}\Delta \text { Number of } \\
\text { leaves }\end{array}$ & \multicolumn{2}{|c}{$\begin{array}{c}\Delta \text { Number of } \\
\text { shoots }\end{array}$} \\
\hline Genotype & Flooding frequency & $N$ & Mean & SE & Mean & SE & Mean & SE \\
\hline LM & low & 8 & 63.38 & 15.13 & 15.88 & 2.43 & 7.00 & 0.82 \\
HM & low & 8 & 37.13 & 9.85 & 18.00 & 3.19 & 8.13 & 1.52 \\
LM & moderate & 8 & 45.28 & 10.35 & 21.75 & 2.45 & 9.50 & 0.78 \\
HM & moderate & 8 & 32.81 & 11.76 & 16.88 & 3.42 & 8.50 & 1.65 \\
LM & high & 8 & 45.63 & 18.10 & 10.43 & 1.53 & 6.25 & 1.18 \\
HM & high & 8 & 9.94 & 2.91 & 8.86 & 0.80 & 5.88 & 1.08 \\
\hline
\end{tabular}

ing photosynthesis (Johnson, 2016), so its reduction can be interpreted as a reduction in performance as well. In contrast to the high-marsh genotype showing a marked reduction in aboveground biomass, the low-marsh genotype maintained aboveground biomass across all flooding treatments.

We also found a decrease in belowground biomass with increasing flooding frequency in both genotypes. This can be interpreted as an adaptive trait, because a reduction of belowground biomass reduces the number of respiring roots and thereby improves the diffusion of oxygen to the roots (Naidoo and Naidoo, 1992; Voesenek et al., 1988). In line with these results, an increased aboveground biomass production while belowground biomass decreased was found for other flooding-adapted plant species such as Taxodium distichum, Danthonia montevidensis and Paspalum dilatatum (Megonigal and Day, 1992; Rubio et al., 1995).

The difference in aboveground biomass response between the two genotypes seems to be mainly explained by genotype-specific increases in leaf and shoot length, whereas the number of both remained similar (Fig. 2, Table 1). Likewise, Voesenek et al. (1988) found a marked increase in leaf length in the flooding-adapted Rumex palustris under waterlogging but no increase in number of leaves. The distinct increase in leaf and shoot length, in addition to the simultaneous reduction of belowground biomass of the lowmarsh genotype of Elymus athericus found in our study, indicates resource allocation as a response to flooding. For other species it was found that reallocated resources fuel the elongation of shoots and leaves to maintain gas exchange and avoid light dissipation through water (Blanch et al., 1999; Grace, 1989). Our results suggest that this response may be also present in E. athericus, which could improve its chances of survival under higher flooding frequencies e.g. due to accelerated SLR.

Vertical accretion in the minerogenic salt marshes of the Wadden Sea is primarily driven by sedimentation (Allen, 2000; Nolte et al., 2013b), which is strongly controlled by the sediment-trapping capacity of the aboveground biomass (Morris et al., 2002; Yang, 1998). The strong aboveground biomass response to increased flooding frequencies of the low-marsh genotype found in our study may therefore have a positive effect on vertical accretion rates and thereby marsh resilience to rising sea levels. 
E. athericus is not the only salt-marsh species characterised by a high degree of genetic diversity. In previous studies, genotypes of several salt-marsh grasses have been described and tested for intraspecific differences in plant response to changing environmental conditions, including Puccinellia maritima, Phragmites australis and Spartina alterniflora (Gray, 1985; Mozdzer and Megonigal, 2012; Proffitt et al., 2003; Seliskar et al., 2002). They showed high genotypic variations affecting colonisation success, species composition and even ecosystem function.

Compared to the root biomass of both genotypes, which responded similarly and decreased with increasing flooding frequency, rhizome length differed significantly between the genotypes (Table 1). The formation of longer rhizomes by the low-marsh genotype, especially under high flooding frequency, could serve as an escape strategy to expand into more favourable habitats (Hartnett and Bazzaz, 1983; Lovett-Doust, 1981). In previous studies, it was reported that E. athericus usually expands via a "phalanx" growth strategy, which means that parental plants invest in many but rather short rhizomes to utilise resources in a favourable habitat (Bockelmann and Neuhaus, 1999). Field observations of the same authors and results of our study, however, indicate that E. athericus is able to alter its strategy to the "guerrilla" form by producing longer rhizomes. The "guerrilla" strategy is usually found in plants characteristic for early successional stages as it enables plants to spread quickly and exploit new favourable areas (Lovett-Doust, 1981). However, overall rhizome length of our study should be interpreted with caution because of potential edge effects caused by the experimental mesocosms.

The change of expansion strategy together with a better adaptation to higher flooding frequencies may lead to a displacement of the high-marsh genotype under accelerated SLR. However, until now, the Wadden Sea salt marshes have been able to cope with current rates of sea level rise due to high accretion rates (Esselink et al., 2017; Nolte et al., 2013a). If rates of SLR remain stable, the low-marsh genotype of the tall grass $E$. athericus has the potential to expand further into the low marsh and outcompete other species via light competition, potentially reducing local species diversity.

\section{Methodological considerations}

We suggest that the experimental setup including a tidal tank and steps proved suitable to investigate the effects of different flooding frequencies on salt-marsh vegetation. Nevertheless, we recommend repeating this experiment in situ, for example as a transplant experiment, to estimate actual effect size under more natural conditions, as drainage and plant-soil interactions might have been different in the tidal tank and could have affected biomass production.

\section{Conclusions}

The present work revealed marked differences in the plant biomass response to changes in flooding frequency between two genotypes of the dominant European salt-marsh grass Elymus athericus. Furthermore, we observed large differences in rhizome production between genotypes, which is interpreted as a change in growth strategy. The alteration of its growth strategy and the higher aboveground biomass productivity of the low-marsh genotype implies a larger potential of the low-marsh genotype to invade and establish at lower elevations of the tidal frame. Considering the generally low plant species diversity of salt marshes (e.g. Silliman, 2014; Wanner et al., 2014) and the strong feedbacks between plant growth and accelerated SLR (Kirwan and Megonigal, 2013), it is possible that intraspecific variation and adaptive capacity in salt-marsh plants act as important but overlooked mediators of ecosystem resilience.

Data availability. All data presented in this paper are available from the corresponding author upon request.

Author contributions. All authors contributed to the design of the experiments. SR and HT conducted the experiment and performed the measurements. SR analysed the data and wrote the manuscript. All authors contributed to the discussion of results and the final manuscript.

Competing interests. The authors declare that they have no conflict of interest.

Acknowledgements. We would like to thank Chris Smit and his colleagues from the University of Groningen for the provision of the plants. Furthermore, we would like to acknowledge Max Beiße, Marion Klötzl and Maren Winnacker for their assistance during the preparation of the experiment. Christoph Reisdorff provided advice on experimental setup and measurements.

Review statement. This paper was edited by Sara Vicca and reviewed by two anonymous referees.

\section{References}

Allen, J. R. L.: Morphodynamics of Holocene salt marshes: a review sketch from the Atlantic and Southern North Sea coasts of Europe, Quaternary Sci. Rev., 19, 1155-1231, 2000.

Bakker, J. P., Bos, D., and De Vries, Y.: To graze or not to graze: that is the question, in: Challenges to the Wadden Sea area - Proceedings of the 10th international Scientific Wadden Sea Symposium, edited by: Essink, K., van Leeuwe, M., Kellermann, A., 
and Wolff, W. J., 31 October-3 November 2000, Dutch Ministry of Agriculture, Nature management and Fisheries, 67-87, 2003.

Beierkuhnlein, C., Thiel, D., Jentsch, A., Willner, E., and Kreyling, J.: Ecotypes of European grass species respond differently to warming and extreme drought, J. Ecol., 99, 703-713, https://doi.org/10.1111/j.1365-2745.2011.01809.x, 2011.

Blanch, S. J., G. Ganf, G., and Walker, K. F.: Growth and resource allocation in response to flooding in the emergent sedge Bolboschoenus medianus, Aquat. Bot., 63, 145-160, https://doi.org/10.1016/S0304-3770(98)00109-0, 1999.

Bockelmann, A. C. and Neuhaus, R.: Competitive exclusion of Elymus athericus from a high-stress habitat in a European salt marsh, J. Ecol., 87, 503-513, 1999.

Bockelmann, A. C., Bakker, J. P., Neuhaus, R., and Lage, J.: The relation between vegetation zonation, elevation and inundation frequency in a Wadden Sea salt marsh, Aquat. Bot., 73, 211-221, https://doi.org/10.1016/S0304-3770(02)00022-0, 2002.

Bockelmann, A. C., Reusch, B. H., Bijlsma, R., and Bakker, J. P.: Habitat differentiation vs. isolation-by-distance: The genetic population structure of Elymus athericus in European salt marshes, Mol. Ecol., 12, 505-515, https://doi.org/10.1046/j.1365-294X.2003.01706.x, 2003.

Bolhuis, H., Fillinger, L., and Stal, L. J.: Coastal microbial mat diversity along a natural salinity gradient, PLoS One, 8, e63166, https://doi.org/10.1371/journal.pone.0063166, 2013.

Bolle, L. J., Neudecker, T., Vorberg, R., Damm, U., Diederichs, B., Jager, Z., Scholle, J., Daenhardt, A., Lüerßen, G., and Marencic, H.: Trends in Wadden Sea Fish Fauna, Part I: Trilateral Cooperation (Report No. C108/08), Wageningen IMARES, IJmuiden, 2009.

Box, G. E. P.: Some theorems on quadratic forms applied in the study of analysis of variance problems, I. Effect of inequality of variance in the one-way classification, Ann. Math. Stat., 25, 290-302, https://doi.org/10.1214/aoms/1177728786, 1954.

Chmura, G. L.: What do we need to assess the sustainability of the tidal salt marsh carbon sink?, Ocean Coast. Manage., 83, 25-31, https://doi.org/10.1016/j.ocecoaman.2011.09.006, 2013.

Duarte, C. M., Dennison, W. C., Orth, R. J. W., and Carruthers, T. J. B.: The charisma of coastal ecosystems: Addressing the imbalance, Estuar. Coast., 31, 233-238, https://doi.org/10.1007/s12237-008-9038-7, 2008.

Eleuterius, L. N. and Eleuterius, C. K.: Tide levels and salt marsh zonation, B. Mar. Sci., 29, 394-400, 1979.

Esselink, P., Duin, W. E. Van, Bunje, J., Cremer, J., Folmer, E. O., Frikke, J., Glahn, M., Groot, A. V. De, Hecker, N., Hellwig, U., Jensen, K., Körber, P., Petersen, J., and Stock, M.: Salt marshes, Wadden Sea Qual. Status Rep., edited by: Kloepper, S., Strempel R., Bostelmann, A., and Busch, J., Common Wadden Sea Secret, Wilhelmshaven, Germany, 2017.

Fitzgerald, D. M., Fenster, M. S., Argow, B. A., and Buynevich, I. V.: Coastal impacts due to sea-level rise, Annu. Rev. Earth Pl. Sc., 36, 601-647, 2008.

Grace, J. B.: Effects of water depth on Typha latifolia and Typha domingensis, Am. J. Bot., 76, 762-768, 1989.

Gray, A. J.: Adaptation in perennial coastal plants - with particular reference to heritable variation in Puccinellia maritima and Ammophila arenaria, Vegetatio, 61, 179-188, 1985.

Hanke, J. M., Ludewig, K., and Jensen, K.: Effects of water level and competition on the endangered river corridor plant Cnidium dubium in the context of climate change, Wetl. Ecol. Manag., 23, 215-226, https://doi.org/10.1007/s11273-014-9371-5, 2015.

Hartnett, D. C. and Bazzaz, F. A.: Physiological integration among intraclonal ramets in Solidago Canadensis, Ecology, 64, 779788, 1983.

Johnson, M. P.: Photosynthesis, Essays Biochem., 60, 255-273, https://doi.org/10.1042/EBC20160016, 2016.

Kirwan, M. L. and Guntenspergen, G. R.: Feedbacks between inundation, root production, and shoot growth in a rapidly submerging brackish marsh, J. Ecol., 100, 764-770, https://doi.org/10.1111/j.1365-2745.2012.01957.x, 2012.

Kirwan, M. L. and Guntenspergen, G. R.: Response of plant productivity to experimental flooding in a stable and a submerging marsh, Ecosystems, 18, 903-913, https://doi.org/10.1007/s10021-015-9870-0, 2015.

Kirwan, M. L. and Megonigal, J. P.: Tidal wetland stability in the face of human impacts and sea-level rise, Nature, 504, 53-60, https://doi.org/10.1038/nature12856, 2013.

Langley, J. A., Mozdzer, T. J., Shepard, K. A., Hagerty, S. B., and Megonigal, J. P.: Tidal marsh plant responses to elevated $\mathrm{CO}_{2}$, nitrogen fertilization, and sea level rise, Glob. Change Biol., 19, 1495-1503, https://doi.org/10.1111/gcb.12147, 2013.

Lovett-Doust, L.: Population dynamics and local specialization in a clonal perennial (Ranunculus Repens): II. The dynamics of leaves, and a reciprocal transplant-replant experiment, J. Ecol., 69, 757-768, https://doi.org/10.2307/2259634, 1981.

McGuinness, K. A.: Of rowing boats, ocean liners and tests of the ANOVA homogeneity of variance assumption, Austral Ecol., 27, 681-688, https://doi.org/10.1046/j.1442-9993.2002.01233.x, 2002.

McLeod, E., Chmura, G. L., Bouillon, S., Salm, R., Björk, M., Duarte, C. M., Lovelock, C. E., Schlesinger, W. H., and Silliman, B. R.: A blueprint for blue carbon: Toward an improved understanding of the role of vegetated coastal habitats in sequestering $\mathrm{CO}_{2}$, Front. Ecol. Environ., 9(, 552-560, 2011.

Megonigal, J. P. and Day, F. P.: Effects of flooding on root and shoot production of Bald Cypress in large experimental enclosures, Ecology, 73, 1182-1193, 1992.

Möller, I., Kudella, M., Rupprecht, F., Spencer, T., Paul, M., Van Wesenbeeck, B. K., Wolters, G., Jensen, K., Bouma, T. J., Miranda-Lange, M., and Schimmels, S.: Wave attenuation over coastal salt marshes under storm surge conditions, Nat. Geosci., 7, 727-731, https://doi.org/10.1038/NGEO2251, 2014.

Morris, J. T., Sundareshwar, P. V., Nietch, C. T., Kjerfve, B., and Cahoon, D. R.: Responses of coastal wetlands to rising sea level, Ecology, 83, 2869-2877, 2002.

Morris, J. T., Sundberg, K., and Hopkinson, C. S.: Salt marsh primary production and its responses to relative sea level and nutrients, Oceanography, 26, 78-84, 2013.

Mozdzer, T. J. and Megonigal, J. P.: Jack-and-Master trait responses to elevated $\mathrm{CO}_{2}$ and $\mathrm{N}$ : A comparison of native and introduced Phragmites australis, PLoS One, 7, https://doi.org/10.1371/journal.pone.0042794, 2012.

Naidoo, G. and Naidoo, S.: Waterlogging responses of Sporobolus-Virginicus (L) Kunth, Oecologia, 90, 445-450, https://doi.org/10.1007/BF00317704, 1992.

Nolte, S., Müller, F., Schuerch, M., Wanner, A., Esselink, P., Bakker, J. P., and Jensen, K.: Does livestock grazing affect sediment deposition and accretion rates in 
salt marshes?, Estuar. Coast. Shelf S., 135, 296-305, https://doi.org/10.1016/j.ecss.2013.10.026, 2013a.

Nolte, S., Koppenaal, E. C., Esselink, P., Dijkema, K. S., Schuerch, M., De Groot, A. V., Bakker, J. P., and Temmerman, S.: Measuring sedimentation in tidal marshes: A review on methods and their applicability in biogeomorphological studies, J. Coast. Conserv., 17, 301-325, https://doi.org/10.1007/s11852-013-0238-3, 2013 b.

Nolte, S., Wanner, A., Stock, M., and Jensen, K.: Elymus athericus encroachment in Wadden Sea salt marshes is driven by surface elevation change, Appl. Veg. Sci., 22, 454-464, https://doi.org/10.1111/avsc.12443, 2019.

Olff, H., De Leeuw, J., Bakker, J. P., Platerink, R. J., and van Wijnen, H. J.: Vegetation succession and herbivory in a salt marsh: Changes induced by sea level rise and silt deposition along an elevational gradient, J. Ecol., 85, 799-814, 1997.

Proffitt, C. E., Travis, S. E., and Edwards, K. R.: Genotype and elevation influence Spartina alterniflora colonization and growth in a created salt marsh, Ecol. Appl., 13, 180-192, 2003.

Razgour, O., Forester, B., Taggart, J. B., Bekaert, M., Juste, J., Ibáñez, C., Puechmaille, S. J., Novella-Fernandez, R., Alberdi, A., and Manel, S.: Considering adaptive genetic variation in climate change vulnerability assessment reduces species range loss projections, P. Natl. Acad. Sci. USA, 116, 10418-10423, https://doi.org/10.1073/pnas.1820663116, 2019.

Rubio, G., Casasola, G., and Lavado, R. S.: Adaptations and biomass production of two grasses in response to water logging and soil nutrient enrichment, Oecologia, 102, 102-105, 1995.

Schuerch, M., Spencer, T., Temmerman, S., Kirwan, M. L., Wolff, C., Lincke, D., Mcowen, C. J., Pickering, M. D., Reef, R., Vafeidis, A. T., Hinkel, J., Nicholls, R. J., and Brown, S.: Future response of global coastal wetlands to sea-level rise, Nature, 561, 231-234, https://doi.org/10.1038/s41586-018-0476-5, 2018
Seliskar, D. M., Gallagher, J. L., Burdick, D. M., and Mutz, L. A.: The regulation of ecosystem functions by ecotypic variation in the dominant plant: a Spartina alterniflora salt-marsh case study, J. Ecol., 90, 1-11, 2002.

Silliman, B. R.: Quick guide: Salt marshes, Curr. Biol., 24, 348350, https://doi.org/10.1016/j.cub.2014.03.001, 2014.

Valladares, F., Matesanz, S., Guilhaumon, F., Araújo, M. B., Balaguer, L., Benito-Garzón, M., Cornwell, W., Gianoli, E., van Kleunen, M., Naya, D. E., Nicotra, A. B., Poorter, H., and Zavala, M. A.: The effects of phenotypic plasticity and local adaptation on forecasts of species range shifts under climate change, Ecol Lett., 17, 1351-1364, https://doi.org/10.1111/ele.12348, 2014.

Veeneklaas, R. M., Dijkema, K. S., Hecker, N., and Bakker, J. P.: Spatio-temporal dynamics of the invasive plant species Elytrigia atherica on natural salt marshes, Appl. Veg. Sci., 16, 205-216, https://doi.org/10.1111/j.1654-109X.2012.01228.x, 2013.

Voesenek, L. A. C. J., Blom, C. W. P. M., and Pouwels, R. H.: Root and shoot development of Rumex species under waterlogged conditions, Can. J. Botany, 67, 1865-1869, https://doi.org/10.1139/b89-236, 1988.

Wanner, A., Suchrow, S., Kiehl, K., Meyer, W., Pohlmann, N., Stock, M., and Jensen, K.: Scale matters: Impact of management regime on plant species richness and vegetation type diversity in Wadden Sea salt marshes, Agr. Ecosyst. Environ., 182, 69-79, https://doi.org/10.1016/j.agee.2013.08.014, 2014.

Yang, S. L.: The role of Scirpus marsh in attenuation of hydrodynamics and retention of fine sediment in the Yangtze estuary, Estuar. Coast. Shelf S., 47, 227-233, 1998. 